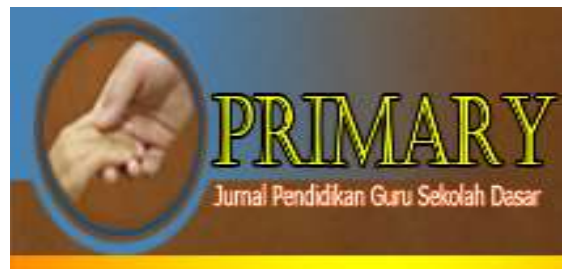

\author{
PRIMARY: JURNAL PENDIDIKAN GURU SEKOLAH DASAR \\ VOLUME 10 NOMOR 3 JUNI 2021 \\ ISSN : 2303-1514 | E-ISSN : 2598-5949 \\ DOI : http://dx.doi.org/10.33578/jpfkip.v10i3.8378 \\ https://primary.ejournal.unri.ac.id/index.php/JPFKIP
}

\title{
IMPLEMENTATION OF CLINICAL SUPERVISION WITH A LESSON STUDY APPROACH THROUGH ZOOM MEETING IN IMPROVING TEACHER PROFESSIONALISM
}

\section{Darwis B}

SMAN 1 Kampar, Kampar, Indonesia

darwis.b.kd@gmail.com

\section{PENERAPAN SUPERVISI KLINIS DENGAN PENDEKATAN LESSON STUDY MELALUI ZOOM MEETING DALAM MENINGKATKAN PROFESIONALISME GURU}

\begin{tabular}{|c|c|}
\hline ARTICLE HISTORY & ABSTRACT \\
\hline $\begin{array}{l}\text { Submitted: } \\
18 \text { Desember } 2020 \\
18^{\text {th }} \text { December } 2020\end{array}$ & $\begin{array}{l}\text { Abstract: This study aims to improve teacher professionalism through the application of } \\
\text { clinical supervision with a lesson study approach through zoom meetings in Kampar District, } \\
\text { Kampar Regency. This research is action research with the lesson study approach. Research } \\
\text { data were collected through questionnaires and observation sheets. The data collected are in } \\
\text { the form of teaching simulation scores and the design scores of the Learning Implementation } \\
\text { Plan. The research subjects were } 36 \text { teachers in Kampar District, Kampar Regency. The } \\
\text { research analysis technique used descriptive analysis. The results showed that in the first cycle, } \\
\text { the score was } 80.08 \text { in the good category, while in the second cycle, the score was } 83.85 \text { in the } \\
\text { good category. Thus, that the application of clinical supervision with a lesson study approach } \\
\text { through zoom meetings that are carried out continuously and consistently results in significant } \\
\text { changes in learning improvement and at the same time increasing teacher performance and } \\
\text { professionalism. }\end{array}$ \\
\hline
\end{tabular}

Accepted:

20 Mei 2021

$20^{\text {th }}$ May 2021

Keywords: clinical supervision, lesson study, teacher professionalism

Abstrak: Penelitian ini bertujuan meningkatkan profesionalisme guru melalui penerapan supervisi klinis dengan pendekatan lesson study melalui zoom meeting di Kecamatan Kampar Kabupaten Kampar. Penelitian ini merupakan penelitian tindakan dengan pendekatan lesson study. Data penelitian dikumpulkan melalui lembar kuisioner dan observasi. Data yang dikumpulkan berupa skor simulasi mengajar dan skor rancangan Rencana Pelaksanaan Pembelajaran. Adapun subyek penelitian adalah guru-guru di Kecamatan Kampar Kabupaten Kampar sebanyak 36 orang. Teknik analisis penelitian menggunakan analisis deskriptif. Hasil penelitian menunjukkan pada siklus I memperoleh skor 80.08 dengan kategori baik, sedangkan pada siklus II memperoleh skor 83.85 dengan kategori baik. Dengan demikian, bahwa

Published:

27 Juni 2021

$27^{\text {th }}$ June 2021 penerapan supervisi klinis dengan pendekatan lesson study melalui zoom meeting yang dilaksanakan secara berkesinambungan dan konsisten menghasilkan perubahan yang signifikan terhadap perbaikan pembelajaran dan sekaligus meningkatkan kinerja dan profesionalisme guru.

Kata Kunci: supervisi klinis, lesson study, profesionalisme guru

\section{CITATION}

B. Darwis. (2021). Implementation Of Clinical Supervision With A Lesson Study Approach

Through Zoom Meeting In Improving Teacher Professionalism. Primary: Jurnal Pendidikan Guru Sekolah Dasar, 10 (3), 730-738. DOI: http://dx.doi.org/10.33578/jpfkip.v10i3.8378. 


\section{PENDAHULUAN}

Pendidikan merupakan hal yang sangat penting diperhatikan dan menjadi salah satu tolak ukur kemajuan suatu bangsa. Pendidikan mempunyai peranan yang sangat penting dalam meningkatkan kualitas sumber daya manusia. Sumber daya manusia yang berkualitas dapat membangun dirinya sendiri, membangun masyarakat dan juga mampu membangun bangsa dan negara. Setiap individu dimana pun berada memerlukan pendidikan agar dapat meningkatkan taraf hidupnya. Demikian halnya di Indonesia bahwa setiap warga negara harus mendapat pendidikan yang memadai agar warga negara terhindar dari kebodohan.

Menurut UU No. 20 Tahun 2003 tentang Sistem Pendidikan Nasional bahwa pendidikan adalah usaha sadar dan terencana untuk mewujudkan suasana belajar dan proses pembelajaran agar peserta didik secara aktif mengembangkan potensinya untuk memiliki kekuatan spiritual keagamaan, pengendalian diri, kepribadian, kecerdasan, akhlak mulia, serta keterampilan yang diperlukan dirinya, masyarakat, bangsa dan negara.

Deklarasi guru sebagai tenaga profesional dikemukakan oleh Presiden Republik Indonesia pada akhir tahun 2004, sebagai titik awal pemerintah untuk memperbaiki mutu pendidikan di Indonesia. Pendidik atau guru sebagai agen pembelajaran merupakan tenaga profesional yang bertugas merencanakan dan melaksanakan proses pembelajaran, menilai hasil pembelajaran, melakukan pembimbingan dan pelatihan, serta melakukan penelitian dan pengabdian kepada masyarakat, diharapkan mampu meningkatkan harkat dan martabat kualitas bangsa Indonesia di masa mendatang. Permasalahan yang dihadapi guru di dalam melaksanakan tugas dan fungsinya sebagai agen pembelajaran antara lain, berupa perilaku peserta didik yang tidak mau mengerjakan tugas, tidak mau terlibat secara aktif dalam proses pembelajaran, mengantuk, ngobrol dengan temannya, dan lain-lain yang pada dasarnya merupakan gambaran masih rendahnya motivasi belajar peserta didik.

Permasalahan lain muncul dari pribadi guru sendiri antara lain: tidak adanya persiapan dalam merancang pembelajaran, ketidaksiapan melaksanakan tugas pembelajaran di rumah yang tercermin dalam penguasaan materi ajar yang rendah, proses pembelajaran yang terkesan tidak terprogram, manajemen pembelajaran yang tidak dikelola dengan baik serta ketidakseriusan guru dalam membimbing peserta didik. Guru belum optimal dalam memberi penguatan, keterampilan bertanya, variasi metode dan teknik pembelajaran, memberikan motivasi, membimbing kelompok dan individu sehingga pembelajaran menjadi tidak menarik, tidak menyenangkan dan bahkan monoton (Bafadal, 2003).

Kondisi seperti tersebut di atas, tentu tidak boleh dibiarkan terus menerus. Kepala sekolah sebagai tenaga kependidikan profesional memiliki tugas dan tanggung jawab serta kewenangan penuh untuk melaksanakan pengawasan akademik dan manajerial pada sejumlah satuan pendidikan tertentu melalui kegiatan pemantauan, penilaian, pembinaan pelaporan dan tindak lanjut. Fungsi pengawasan akademik yang dilakukan kepala sekolah terhadap guru di sekolah melalui kegiatan supervisi klinis. Secara spesifik, supervisi klinis dilakukan dengan tujuan untuk memperbaiki kinerja guru berdasarkan hasil diagnosis secara bersamasama antara guru dengan kepala sekolah (Anwar, 2000). Temuan-temuan berupa kelemahan-kelemahan yang dihadapi guru dibahas bersama dan dicarikan solusi pemecahannya yang efektif.

Pelaksanaan supervisi klinis seringkali diabaikan oleh para supervisor, baik kepala sekolah maupun pengawas satuan pendidikan, sehingga guru terkadang mencari caranya sendiri dalam menyelesaikan masalah proses pembelajaran dimasa pandemi ini dan bahkan apa yang dilakukannya tidak tepat dan tidak efektif. Untuk itu, supervisi klinis menjadi sangat penting dilakukan untuk meningkatkan 
profesionalisme guru (Anwar, 2000), sehingga kualitas pembelajaran akan meningkat dan berdampak pada meningkatnya taraf serap peserta didik terhadap materi yang dipelajarinya.

Upaya untuk meningkatkan kualitas kinerja guru dalam pembelajaran daring dan online di samping melalui supervisi klinis, dapat juga dilakukan secara kolaboratif antara sesama guru, kepala sekolah dan pengawas satuan pendidikan. Pendekatan kolaboratif ini disebut dengan lesson study, yakni suatu kegiatan yang dilakukan oleh guru sejenis dengan difasilitasi oleh pengawas satuan pendidikan untuk menyusun disain instruksional, melaksanakan proses pembelajaran, mengamati proses pembelajaran serta merefleksi secara bersama-sama tentang pelaksanaan pembelajaran secara daring tersebut.

Berdasarkan latar belakang tersebut, maka perlu mencari solusinya untuk mengatasi permasalahan guru dalam melaksanakan pembelajaran secara daring dengan supervisi klinis dengan pendekatan lesson study melalui zoom meeting dalam meningkatkan profesionalisme guru.

\section{KAJIAN TEORI}

\section{Kompetensi Guru dan Kompetensi Profesional Guru}

Menurut Bafadal (2003) memahami kompetensi sebagai suatu kemampuan yang disyaratkan untuk memangku profesi. Senada dengan, Sardiman (2020) mengartikan kompetensi adalah kemampuan dasar yang harus dimiliki seseorang berkenaan dengan tugasnya. Guru adalah pendidik profesional dengan tugas utama mendidik, mengajar, membimbing, mengarahkan, melatih, menilai, dan mengevaluasi peserta didik pada pendidikan anak usia dini jalur pendidikan formal, pendidikan dasar, dan pendidikan menengah. Kompetensi guru merupakan seperangkat pengetahuan, ketrampilan, dan perilaku yang harus dimiliki, dihayati, dan dikuasai oleh guru dalam melaksanakan tugas keprofesionalan (Undang-undang No. 14 Tahun 2005 tentang Guru dan Dosen).

Kompetensi profesional guru dapat diukur meliputi :

1. Kompetensi Pedagogik

Kompetensi pedagogik meliputi pemahaman terhadap peserta didik, perancangan dan pelaksanaan Pembelajaran, evaluasi hasil belajar, dan pengembangan peserta didik untuk mengaktualisasikan berbagai potensi yang dimilikinya.

2. Kompetensi Kepribadian

Kompetensi kepribadian merupakan kemampuan personal yang mencerminkan kepribadian yang mantap, stabil, dewasa, arif dan berwibawa, menjadi teladan bagi peserta didik, dan berakhlak muia.

3. Kompetensi Sosial

Kompetensi sosial merupakan kemampuan guru untuk berkomunikasi dan berinteraksi secara efektif dengan peserta didik, sesama pendidik, tenaga kependidikan, orang tua/wali peserta didik, masyarakat sekitar dan lingkungan hidup.

4. Kompetensi Profesional

Kompetensi profesional merupakan penguasaan materi pembelajaran secara luas dan mendalam, yang mencakup penguasaan materi kurikulum mata pelajaran di sekolah, substansi dan metodologi keilmuannya serta keterkaitannya dengan kecakapan hidup dan lingkungan hidup.

\section{Tugas Pokok dan Fungsi Kepala Sekolah}

Merujuk pada Peraturan Pemerintah

No.19 Tahun 2005 tentang Standar Nasional Pendidikan pasal 39 ayat (1) bahwa pengawasan pada pendidikan formal dilakukan oleh kepala sekolah, sedangkan penegasannya dijelaskan pada pasal 55, yaitu pengawasan dimaksud meliputi pemantauan, supervisi, evaluasi, pelaporan dan tindak lanjut hasil pengawasan. Untuk melaksanakan tugas pokok dan fungsi, kepala sekolah menguasai 6 
dimensi kompetensi kepala sekolah, seperti tercantum dalam Peraturan Menteri Pendidikan Nasional No. 12 tahun 2016 tentang Standar Pengawas Sekolah/Madrasah meliputi: kompetensi kepribadian, kompetensi supervisi manajerial, kompetensi supervisi akademik, kompetensi evaluasi pendidikan, kompetensi penelitian pengembangan serta kompetensi sosial.

Richard Waller dalam Purwanto (2006) menyatakan bahwa supervisi klinis merupakan salah satu model supervisi yang difokuskan pada peningkatan kemampuan mengajar melalui siklus yang sistematis, baik dalam perencanaan, pengamatan serta analisis yang intensif tentang penampilan mengajar yang nyata, serta berujuan mengadakan perubahan dengan cara yang rasional. Sementara itu, Keith Acheson dan Meredith D. Gall menyatakan bahwa supervisi klinis adalah proses membantu guru memperkecil kesenjangan antara tingkah laku mengajar yang nyata dengan tingkah laku yang ideal (Purwanto: 2006).

Berdasarkan pendapat di atas, penulis dapat mensintesiskan bahwa supervisi klinis adalah suatu proses bimbingan yang bertujuan untuk membantu pengembangan profesionalitas guru khususnya dalam penampilan mengajar, berdasarkan observasi dan analisis data secara teliti dan objektif sebagai pegangan untuk perubahan tingkah laku mengajar guru.

\section{Pendekatan Lesson Study}

Lesson study merupakan suatu pendekatan peningkatan kualitas pembelajaran yang awal mulanya berasal dari jepang. Di Negara tersebut, kata atau istilah itu lebih popular dengan sebutan jugyokenkyu. lesson study dikembangkan oleh Makoto Yoshida. Menurut Hendayana, dkk (2006) mengemukakan bahwa lesson study adalah suatu model pembinaan profesi pendidik melalui pengkajian pembelajaran secara kolaboratif dan berkelanjutan berlandaskan prinsip-prinsip kolegalitas dan mutual learning untuk membangun learning community (Simatupang dan Aryeni, 2018). Selanjutnya Fernandez dan Yoshida (2004); Lewis (2002) mengemukakan 6 (enam) langkah dalam proses melaksanakan suatu lesson study. Keenam langkah itu adalah (1) membentuk group lesson study, (2) memfokuskan lesson study, (3) merencanakan research lesson (pelajaran yang diteliti), (4) mengajar dan mengamati research lesson, (5) mendiskusikan dan menganalisis research lesson. Dalam Undang-undang Nomor 14 tahun 2005 tentang Guru dan Dosen yang menyatakan bahwa dalam melaksanakan tugas keprofesionalan guru berkewajiban: (a) merencanakan pembelajaran, melaksanakan proses pembelajaran yang ber, dan (6) merefleksikan lesson study. Lesson study dilaksanakan dalam tiga tahapan yaitu plan (merencanakan), do (melaksanakan), dan see (merefleksi) yang berkelanjutan.

\section{METODE PENELITIAN}

Metode penelitian yang digunakan adalah penelitian tindakan (Arikunto, 2015) yang dilakukan dua siklus, dimana setiap siklus terdiri dari kegiatan perencanaan, tindakan, pengamatan dan refleksi. Subyek penelitian adalah guru yang berasal sekolah yang berada di Kecamatan Kampar sebanyak 36 orang. Instrumen penelitian berupa lembar kuisioner dan lembar observasi yang dibagikan kepada guru. Skala pengukuran yang digunakan dalam instrumen penelitian ini menggunakan skor dengan sistem penilaian satu hingga lima poin. Penelitian juga dilakukan melalui observasi/pengamatan untuk data yang bersifat kualitatif, dilakukan dengan mengamati aktivitas guru dalam pembuatan RPP, kegiatan lesson study serta pelaksanaan PBM melalui daring. Selain itu, peneliti melalukan wawancara teknik supervisi klinis setelah selesai melakukan simulasi mengajar. Teknik analisis penelitian menggunakan analisis deskriptif. 
ISSN : 2303-1514 | E-ISSN : 2598-5949

\section{HASIL DAN PEMBAHASAN}

Pelaksananan penelitian tindakan dilakukan selama dua siklus, dimana pada masing-masing siklus terdiri dari kegiatan perencanaan, pelaksanaan, pengamatan dan refleksi. Untuk lebih jelasnya dapat dilihat pada deskripsi berikut.

\section{Siklus Pertama}

\section{a) Perencanaan Siklus Pertama}

Pada siklus pertama ini, peneliti melakukan tindakan dengan melaksanakan pertemuan awal dengan dua untuk sekolah binaan pada bulan Agustus 2020 dengan memberikan pengarahan dan pembinaan terhadap guru dalam rangka supervisi akademik/supervisi klinis dengan materi penggunaan metode/strategi/teknik pembelajaran yang diawali dengan simulasi mengajar/tutor sebaya.

\section{b) Pelaksanaan Siklus Pertama}

Pelaksanaan kegiatan pembinaan guru melalui supervisi klinis dengan pendekatan kolaboratif dilaksanakan satu kali. Hasilnya rata-rata kehadiran guru sesuai sampel mencapai $100 \%$. (hadir semua). Ini menunjukkan bahwa para guru sangat antusias untuk mengikuti kegiatan pembinaan yang dilakukan Kepala Sekolah.

Hasil pemantauan melakukan simulasi mengajar/tutor sebaya dengan menggunakan RPP dengan menggunakan pendekatan lesson study tergambar dalam tabel di bawah ini:

(1) Hasil Pemantauan Kegiatan Simulasi Mengajar

Tabel 2. Rata-Rata Hasil kegiatan Simulasi Mengajar pada Siklus I

\begin{tabular}{lllll}
\hline \multirow{2}{*}{ No } & \multirow{2}{*}{ Pertemuan } & \multicolumn{3}{c}{ Skor } \\
\cline { 2 - 5 } 1 & I & Kelompok I & Kelompok II & Rata2 \\
2 & II & 73.94 & 73.83 & 73.89 \\
\hline Rata-Rata & 75.44 & 75.39 & 75.42 \\
\hline
\end{tabular}

(2) Sikap Peserta selama kegiatan simulasi mengajar

Tabel 3. Rata-Rata Hasil Sikap Peserta Selama Mengikuti Kegiatan Simulasi Mengajar/Tutor Sebaya

\begin{tabular}{lllll}
\hline \multirow{2}{*}{ No } & \multirow{2}{*}{ Pertemuan } & \multicolumn{3}{c}{ Skor } \\
\cline { 3 - 5 } & Kelompok I & Kelompok II & Rata2 \\
\hline 1 & I & 76.17 & 77.06 & 76.62 \\
2 & II & 78.00 & 78.78 & 78.39 \\
\hline Rata-Rata & & & $\mathbf{7 7 . 5 0}$ \\
\hline
\end{tabular}

(3) Membuat Rencana Pelaksanaan Pembelajaran (RPP)

Tabel 4. Rata-Rata Nilai untuk Pembuatan RPP pada Siklus Pertama

\begin{tabular}{lllll}
\hline \multirow{2}{*}{ No } & \multirow{2}{*}{ Pertemuan } & \multicolumn{3}{c}{ Skor } \\
\cline { 3 - 5 } & & Kelompok I & Kelompok II & Rata2 \\
\hline 1 & I & 75.50 & 77.00 & 76.25 \\
2 & II & 77.22 & 78.67 & 77.95 \\
\hline Rata-Rata & & & $\mathbf{7 7 . 1 0}$ \\
\hline
\end{tabular}


ISSN : 2303-1514 | E-ISSN : 2598-5949

(4) Hasil Pemantauan Pelaksanaan

Pertama

Simulasi Mengajar pada Siklus

Tabel 5. Rata-Rata Hasil Kegiatan Pelaksanaan Proses Belajar Mengajar pada Siklus Pertama

\begin{tabular}{lllll}
\hline No & Pertemuan & \multicolumn{3}{c}{ Skor } \\
\cline { 3 - 5 } & & Kelompok I & Kelompok II & Rata2 \\
\hline 1 & I & 79.17 & 79.39 & 79.28 \\
2 & II & 81.00 & 80.78 & 80.89 \\
\hline Rata-Rata & & & $\mathbf{8 0 . 0 9}$ \\
\hline
\end{tabular}

c) Refleksi dan Evaluasi

Hasil Penelitian Siklus Pertama dinyatakan dalam tabel berikut :

Tabel 6. Rekapitulasi Hasil Pemantauan Siklus Pertama

\begin{tabular}{cccc}
$\begin{array}{c}\text { Rata-Rata Hasil } \\
\text { Simulasi Mengajar }\end{array}$ & $\begin{array}{c}\text { Sikap Peserta Selama } \\
\text { Simulasi Mengajar }\end{array}$ & $\begin{array}{c}\text { Rata-Rata Nilai } \\
\text { Pembuatan RPP }\end{array}$ & $\begin{array}{c}\text { Rata-Rata Nilai } \\
\text { PBM }\end{array}$ \\
\hline $\mathbf{7 4 . 6 5}$ & $\mathbf{7 7 . 5 0}$ & $\mathbf{7 7 . 1 0}$ & $\mathbf{8 0 . 0 9}$ \\
Baik & Baik & Baik & Baik \\
\hline
\end{tabular}

Berdasarkan kegiatan dalam siklus pertama, peneliti dapat mengevaluasi bahwa kegiatan supervisi klinis dengan pendekatan lesson study dapat dilanjutkan dalam kegiatan pembinaan guru di sekolah oleh kepala sekolah.

\section{Siklus Kedua}

\section{a) Perencanaan Siklus Kedua}

Seperti terlihat dalam siklus pertama bahwa tindakan pada siklus kedua ini akan melakukan strategi yang berbeda meskipun tidak semuanya, yaitu supervisi klinis dengan menggunakan pendekatan kolaboratif/lesson study. Strategi ini dipilih agar pembinaan terhadap guru di sekolah lebih transparan, komunikatif dan saling melengkapi antar sesama guru.

\section{b) Pelaksanaan Siklus Kedua}

Siklus ini merupakan siklus terakhir dalam penelitian tindakan sekolah. Adapun gambarannya dapat dilihat dalam tabel berikut ini:

(1) Hasil Pemantauan Kegiatan Simulasi Mengajar

Tabel 7. Rata-Rata Hasil kegiatan Simulasi Mengajar pada Siklus Kedua

\begin{tabular}{lllll}
\multirow{2}{*}{ No } & \multirow{2}{*}{ Pertemuan } & \multicolumn{3}{c}{ Skor } \\
\cline { 3 - 5 } & & Kelompok I & Kelompok II & Rata2 \\
\hline 1 & I & 78.56 & 78.00 & 78.28 \\
2 & II & 81.00 & 80.78 & 80.89 \\
\hline Rata-Rata & & & $\mathbf{7 9 . 5 9}$ \\
\hline
\end{tabular}

(2) Sikap Peserta selama kegiatan simulasi mengajar 


\section{PRIMARY: JURNAL PENDIDIKAN GURU SEKOLAH DASAR \\ VOLUME 10 NOMOR 3 JUNI 2021 \\ ISSN : 2303-1514 | E-ISSN : 2598-5949 \\ DOI : http://dx.doi.org/10.33578/jpfkip.v10i3.8378 \\ https://primary.ejournal.unri.ac.id/index.php/JPFKIP}

Tabel 8. Rata-Rata Hasil Sikap Peserta selama Mengikuti Kegiatan Simulasi Mengajar/Tutor Sebaya

\begin{tabular}{lllll}
\multicolumn{5}{c}{ Kegiatan Simulasi Mengajar/Tutor Sebaya } \\
\cline { 3 - 5 } \multirow{2}{*}{ No } & \multirow{2}{*}{ Pertemuan } & Kelompok I & Kelompok II & Rata2 \\
\cline { 3 - 5 } 1 & I & 80.00 & 80.78 & 80.39 \\
2 & II & 82.22 & 82.78 & 82.50 \\
\hline \multicolumn{2}{l}{ Rata-Rata } & & $\mathbf{8 1 . 4 5}$ \\
\hline
\end{tabular}

(3) Membuat Rencana Pelaksanaan

Pembelajaran (RPP)

Tabel 9. Rata-Rata Nilai untuk Pembuatan RPP pada Siklus Kedua

\begin{tabular}{lrrrc}
\hline \multirow{2}{*}{ No } & \multirow{2}{*}{ Pertemuan } & \multicolumn{3}{c}{ Skor } \\
\cline { 3 - 5 } & I & Kelompok I & Kelompok II & Rata2 \\
\hline 1 & II & 89.22 & 80.67 & 79.95 \\
2 & 81.22 & 82.67 & 81.95 \\
\hline \multicolumn{2}{l}{ Rata-Rata } & & & $\mathbf{8 0 . 9 5}$ \\
\hline
\end{tabular}

(5) Hasil Pemantauan Pelaksanaan

Simulasi Mengajar pada Siklus

Pertama

Tabel 10. Rata-Rata Hasil Kegiatan Pelaksanaan Proses Belajar Mengajar pada Siklus Kedua

\begin{tabular}{lrrrr}
\hline \multirow{2}{*}{ No } & \multirow{2}{*}{ Pertemuan } & \multicolumn{3}{c}{ Skor } \\
\cline { 3 - 5 } & & Kelompok I & Kelompok II & Rata2 \\
\hline 1 & I & 83.00 & 82.72 & 82.86 \\
2 & II & 85.11 & 84.56 & 84.84 \\
\hline \multicolumn{2}{l}{ Rata-Rata } & & & $\mathbf{8 3 . 8 5}$ \\
\hline
\end{tabular}

c) Refleksi dan Evaluasi

Hasil Penelitian Siklus Pertama dinyatakan dalam tabel berikut :

Tabel 11. Rekapitulasi Hasil Pemantauan Siklus Kedua

\begin{tabular}{cccc}
$\begin{array}{c}\text { Rata-Rata Hasil } \\
\text { Simulasi Mengajar }\end{array}$ & $\begin{array}{c}\text { Sikap Peserta Selama } \\
\text { Simulasi Mengajar }\end{array}$ & $\begin{array}{c}\text { Rata-Rata Nilai } \\
\text { Pembuatan RPP }\end{array}$ & $\begin{array}{c}\text { Rata-Rata } \\
\text { Nilai PBM }\end{array}$ \\
\hline $\mathbf{7 9 . 5 9}$ & $\mathbf{8 1 . 4 5}$ & $\mathbf{8 0 . 9 5}$ & $\mathbf{8 3 . 8 5}$ \\
Baik & Baik & Baik & Baik \\
\hline
\end{tabular}

Berdasarkan siklus kedua kegiatan ini, peneliti sebagai pelaksanan kegiatan supervisi klinis terhadap guru-guru di Kecamatan Kampar dapat menggunakan pendekatan kolaboratif/lesson study. Kepala sekolah dapat mengadaptasi dan menggunkan pendekatan untuk dilanjutkan ke guru. Dilihat perbedaan pada siklus pertama dan siklus kedua terdapat peningkatan presentasi yang cukup signifikan.

\section{Pembahasan}

Setelah menyelesaikan dua siklus dalam penelitian tindakan ini, peneliti dapat melihat hasilnya. Kehadiran guru-guru dalam mengikuti pertemuan sangat bagus, mereka saling berbagi pengetahuan (sharing) dan pemecahan masalah Pembelajaran secara bersama-sama. Adapun aktivitas guru dalam mengikuti pertemuan, khususnya hasil 
kegiatan simulasi mengajar boleh dikatakan baik dengan rata-rata skor pada siklus kedua sebesar 79.59, sementara pada siklus pertama hanya mencapai skor 74.65.

Adapun sikap guru dalam mengikuti kegiatan simulasi mengajar dikatakan baik, dengan rata-rata pada siklus kedua sebesar 81.45 sementara pada siklus pertama hanya mendapat skor 77.50. Pembuatan Rencana Pelaksanaan Pembelajaran (RPP) kenaikannya cukup baik. Hal ini menunjukkan bahwa kegiatan ini terutama pembinaan terhadap guru harus dilakukan secara berkelanjutan. Hasilnya adalah pada siklus kedua memperoleh skor sebesar 80.95, sementara pada siklus pertama mendapat skor 77.10.

Problematika yang dihadapi guru-guru di sekolah sehari-hari sangat kompleks. Persiapan yang baik untuk merencanakan proses pembelajaran, memilih strategi atau metode dan teknik, menyusun skenario Pembelajaran, implementasi Pembelajaran dan evaluasi hasil belajar peserta didik. Di samping itu, guru pun dihadapkan pada berbagai persolan baik pribadinya, peserta didik kondisi sekolah yang belum kondusif. Oleh karena itu, guru sangat membutuhkan bimbingan, pembinaan dan pendampingan dari supervisor, dalam hal ini Kepala Sekolah. Pembimbingan, pembinaan dan pendampingan oleh supervisor sebaiknya dilakukan secara kolaboratif dan berdasarkan asas kesejawatan (partnership), sehingga mereka tidak merasa ragu-ragu, segan untuk menyampaikan permasalahannya.

Salah satu bentuk kegiatan semacam itu yang tepat adalah dengan pendekatan/ metode lesson study. Oleh karena dengan kegiatan kolaboratif antara guru, kepala sekolah dan pengawas, aktivitas supervisi dapat secara leluasa mengumpulkan informasi yang lengkap tentang kesulitan-kesulitan apa yang dihadapi guru-guru dalam melaksanakan tugas profesionalnya. Data atau informasi yang terkumpul dapat dijadikan bahan-bahan untuk mencari jalan pemecahannya terhadap kesulitan yang dihadapi para guru tanpa ada kesan yang menakutkan, menginspeksi, atau bentuk aktivitas yang terkesan kurang disenangi oleh para guru. Jalinan hubungan interpersonal yang harmonis antara supervisor dan guru-guru akan memudahkan komunikasi yang efektif antara kepala sekolah dengan guru dalam mengatasi persoalan-persoalan di sekolah.

Manfaat dari pendekatan lesson study yang dilaksanakan secara berkesinambungan dan konsisten akan menghasilkan perubahan yang signifikan terhadap perbaikan pembelajaran dan sekaligus kinerja guru. Kegiatan lesson study yang terintegrasi dengan kegiatan supervisi klinis akan menhasilkan bentuk pelatihan yang nyata untuk mengatasi kelemahan-kelemahan yang dihadapi guru dengan cara mengajak guru untuk melakukan refleksi terhadap perilaku mengajarnya dan kemudian memperbaikinya.

\section{SIMPULAN DAN REKOMENDASI}

Berdasarkan hasil penelitian tindakan selama dua siklus, hasil temuan, analisis data dan refleksi pada tiap-tiap siklus serta analisis dan pemahasannya, maka peneliti dapat menyimpulkan sebagai berikut : 1) pengawasan akademik yang dilakukan kepala sekolah dengan cara supervisi klinis akan memperoleh data objektif tentang kekurangankekurangan guru dalam pelaksanaan pembelajaran. Guru akan senang hati menyampaikan keluhan-keluhan kepada supervisor dengan situasi yang akrab dan komunikatif. Kepala sekolah dan guru dapat mendiskusikan untuk mencari alternatif pemecahannya, yang akhirnya dapat meningkatkan profesionalisme guru; 2) Pengawasan akademik dengan cara supervisi klinis dengan pendekatan lesson study akan lebih menumbuhkan motivasi guru untuk berprestasi dalam rangka meningkatkan profesionalisme guru; 3) Kepala Sekolah sebagai supervisor sangat strategis dalam upaya meningkatkan profesionalisme guru yang akan berdampak pada peningkatan kualitas pembelajaran di sekolah. 
Upaya meningkatkan profesionalitas guru hendaknya dilakukan dengan kegiatan pendampingan, pembinaan oleh kepala sekolah. Pembimbingan yang efektif sebaiknya dilakukan melalui kegiatan supervisi klinis dengan pendekatan lesson study. Oleh karena itu, kepala sekolah senantiasa dapat memfasilitasi kegiatan ini, agar profesionalisme guru di sekolah dapat meningkat secara signifikan.

\section{DAFTAR PUSTAKA}

Anwar, I. (2000). Admistrasi Pendidikan, Teori, Konsep \& Issu. Bandung: UPI

Arikunto, S., Suhardjono., \& Supardi. (2020). Penelitian Tindakan Kelas (Edisi Revisi). Jakarta: Bumi Aksara.

Bafadal, I. (2003). Peningkatan Profesionalisme Guru. Jakarta: Bumi Aksara.

Depdiknas. (2020). Undang-Undang Nomor 20 tahun 2003 tentang Sistem Pendidikan Nasional.

Depdiknas. (2005). Undang-Undang Nomor 14 Tahun 2005 tentang Guru dan Dosen.

Depdiknas. (2005). Peraturan Pemerintah Nomor 19 tahun 2005 tentang Standar Nasional Pendidikan

Depdiknas. (2016). Permendiknas Nomor 16 tahun 2016 tentang Kualifikasi dan kompetensi guru

Depdiknas. (2016). Permendiknas Nomor 12 tahun 2016 tentang Standar Pengawas Sekolah/Madrasah

Fernandez, C., \& Yoshida M. (2004). Lesson Study: A Japanese Approach to Improving Mathematics Teaching and Learning. Mahwah, NJ: Lawrence Erlbaum.

Hendayana, S., Suryadi, D., Muchtar, A., K., Sukirman, A. (2006). Lesson Study: Suatu Strategi untuk Meningkatkan Keprofesionalan Pendidikan (Pengalaman IMSTEP-JICA). Bandung: UPI Press.

Lewis, C. C. (2002). Lesson Study: A Handbook of Teacher-Led Instructional

Purwanto, N. (2006). Administrasi dan Supervisi Pendidikan. Bandung: PT. Remaja Rosdakarya.

Simatupang, H., \& Aryeni. (2018). Model Pendekatan Lesson Study Untuk Meningkatkan Keterampilan Mengajar Mahasiswa pada Mata Kuliah Microteaching. Jurnal Biolokus, 1 (2), 77-83. 